\title{
Layer Thickness-dependent Electrical and Optical Properties of Bottom- and Top-emission Organic Light-emitting Diodes
}

\author{
Hui Chul An, Su Hwan Na, Hyun Woo Joo, and Tae Wan Kim* \\ Department of Information Display Engineering, Hongik University, Sangsu-dong, Mapo-gu, Seoul 121-791, \\ Republic of Korea
}

(Received January 162009 , Accepted February 17 2009)

\begin{abstract}
We have studied organic layer-thickness dependent electrical and optical properties of bottom- and top-emission devices. Bottom-emission device was made in a structure of $\operatorname{ITO}(170 \mathrm{~nm}) / \mathrm{TPD}(x \mathrm{~nm}) / \mathrm{Alq}_{3}(y \mathrm{~nm}) / \mathrm{LiF}(0.5$ $\mathrm{nm}) / \mathrm{Al}(100 \mathrm{~nm})$, and a top-emission device in a structure of glass $/ \mathrm{Al}(100 \mathrm{~nm}) / \mathrm{TPD}(x \mathrm{~nm}) / \mathrm{Alq}_{3}(y \mathrm{~nm}) / \mathrm{LiF}(0.5$ $\mathrm{nm}) / \mathrm{Al}(25 \mathrm{~nm})$. A hole-transport layer of TPD (N,N'-diphenyl-N,N'-di(m-tolyl)-benzidine) was thermally deposited in a range of $35 \mathrm{~nm}$ and $65 \mathrm{~nm}$, and an emissive layer of $\mathrm{Alq}_{3}$ (tris-(8-hydroxyquinoline) aluminum) was successively deposited in a range of $50 \mathrm{~nm}$ and $100 \mathrm{~nm}$. Thickness ratio between the hole-transport layer and the emissive layer was maintained to be $2: 3$, and a whole layer thickness was made to be in a range of 85 and $165 \mathrm{~nm}$. From the current density-luminance-voltage characteristics of the bottom-emission devices, a proper thickness of the organic layer ( $55 \mathrm{~nm}$ thick TPD and $85 \mathrm{~nm}$ thick $\mathrm{Alq}_{3}$ layer) was able to be determined. From the view-angle dependent emission spectrum of the bottom-emission device, the peak wavelength of the spectrum does not shift as the view angle increases. However, for the top-emission device, there is a blue shift in peak wavelength as the view angle increases when the total layer thickness is thicker than $140 \mathrm{~nm}$. This blue shift is thought to be due to a microcavity effect in organic light-emitting diodes.
\end{abstract}

Keywords: $\mathrm{Alq}_{3}$, Organic light-emitting diodes, Microcavity, Top-emission

\section{INTRODUCTION}

Electroluminescent phenomenon in organic semiconductor single crystal was discovered in 1963. And in 1987, Tang and Van Slyke in Eastman Kodak developed organic light-emitting diodes using bilayer device structure[1-3]. Since then, lots of researches are going on[45]. Organic light-emitting diodes have advantages in low operation voltage, low power consumption, fast response time, high efficiency, and etc. Organic light-emitting diodes emit light by a recombination process of electrons and holes injected from a cathode and an anode. Not only the organic material itself but also a thickness of organic layer affect on the device performance. An emission spectrum out of the organic light-emitting diodes is determined by an emissive material and also a type of emission as well. Microcavity structure influences on the emission spectrum, and a dielectric constant and a distance between the mirrors are important factors in organic light-emitting diodes[6-8].

In this paper, we present electrical and optical properties of the bottom- and top-emission organic light-emitting diodes made by varying a thickness of organic layers. View-angle dependent emission spectrum was also studied in those two types of devices.

\section{EXPERIMENTAL DETAILS}

Two different types of organic light-emitting diodes were manufactured with a variation of organic layer thicknesses; one is bottom-emission type and the other is top-emission one. A device structure of $\operatorname{ITO}(170 \mathrm{~nm}) / \mathrm{TPD}(x \mathrm{~nm}) / \mathrm{Alq}_{3}(y$

*Author to whom corresponding should be addressed: electronic mail: taekim@hongik.ac.kr $\mathrm{nm}) / \mathrm{LiF}(0.5 \mathrm{~nm}) / \mathrm{Al}(100 \mathrm{~nm})$ was made for the bottomemission type of device. Here, $x$ and $y$ denote a thickness of each layer in nm unit. An ITO(indium-tin-oxide) was used as an anode, which has a sheet resistance of $10 \Omega / \mathrm{sq}$ and a thickness of $170 \mathrm{~nm}$. A width of patterned ITO strip line was made to be $5 \mathrm{~mm}$. On top of the patterned ITO substrate, hole-transport layer of TPD (N,N'-diphenyl-N,N'di(m-tolyl)-benzidine) was thermally deposited in a range of $35 \mathrm{~nm}$ and $65 \mathrm{~nm}$. And then, an emissive layer of $\mathrm{Alq}_{3}$ (tris-(8-hydroxyquinoline) aluminum) was successively deposited in a range of $50 \mathrm{~nm}$ and $100 \mathrm{~nm}$. Thickness ratio between the hole-transport layer and the emissive layer was maintained to be $2: 3$, and a whole layer thickness was made to be in a range of 85 and $165 \mathrm{~nm}$. A LiF/Al was used as a cathode, and they were separately evaporated under an environment of $5 \times 10^{-6}$ torr. Deposition rate of organics was maintained to be $1.0 \AA / \mathrm{s}$ and an active area of the device was made to be $3 \mathrm{~mm} \times 5 \mathrm{~mm}$. And for the top-emission device, a device structure of glass/Al $(100 \mathrm{~nm}) / \mathrm{TPD}(x$ $\mathrm{nm}) / \mathrm{Alq}_{3}(y \mathrm{~nm}) / \mathrm{LiF}(0.5 \mathrm{~nm}) / \mathrm{Al}(25 \mathrm{~nm})$ was made. A plasma-treated aluminum electrode was used as an anode, which has a thickness of $100 \mathrm{~nm}$ and a width of $5 \mathrm{~mm}$. Oxygen plasma treatment was performed under a condition of $125 \mathrm{~W}$ for 2 minutes, and a partial pressure of oxygen in a chamber was maintained to be $2 \times 10^{-2}$ torr.

Several layer thicknesses of TPD and $\mathrm{Alq}_{3}$ were made, which are same to those of the previous bottom-emission device. Semitransparent metal electrode was made on top of the $\mathrm{Alq}_{3}$ layer with a $\operatorname{LiF}(0.5 \mathrm{~nm}) / \mathrm{Al}(25 \mathrm{~nm})$. Current density-luminance-voltage characteristics were measured using Keithley 236 source-measure unit and Keithley 617 electrometer at room temperature under a control of Test Point program. View-angle dependent emission spectrum was measured using Ocean Optics USB 2000. 

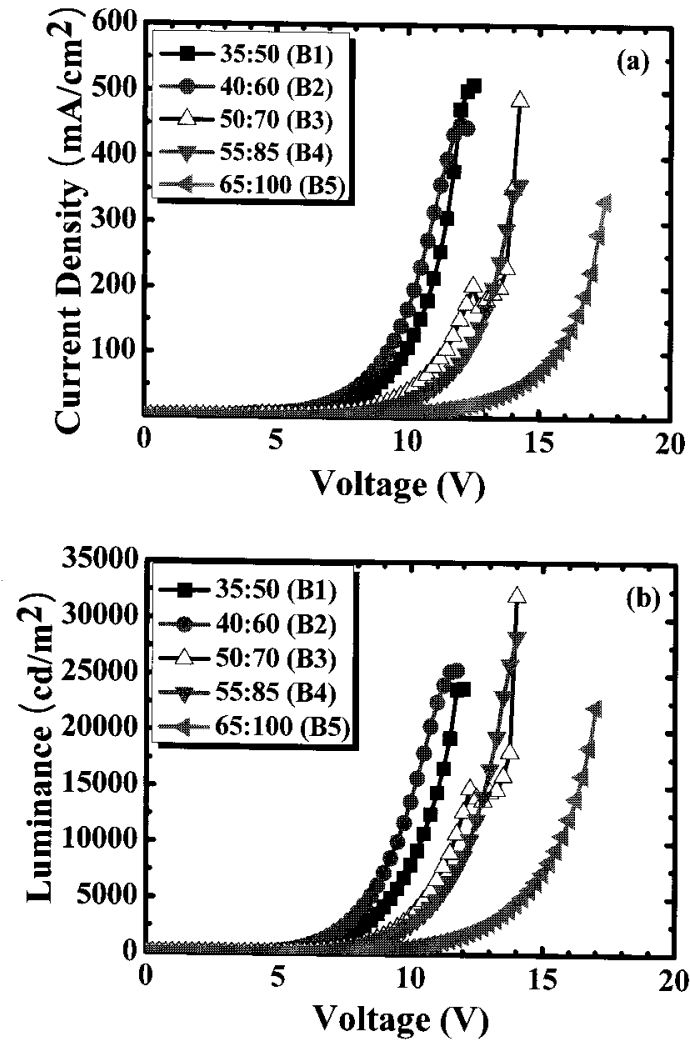

Fig. 1. (a) Current density-voltage characteristics and (b) corresponding luminance-voltage characteristics of $\mathrm{ITO} / \mathrm{TPD} / \mathrm{Alq}_{3} / \mathrm{LiF} / \mathrm{Al}$ bottomemission devices for several different layer thicknesses. The number in inset indicates a layer thickness of TPD and $\mathrm{Alq}_{3}$ in order. And also the letter " $\mathrm{B}$ " in inset indicates a bottom-emission device.

\section{RESULTS AND DISCUSSION}

Figure 1(a) and (b) show the current density-voltage characteristics and the corresponding luminance-voltage characteristics of the bottom-emission devices for several thicknesses of TPD and $\mathrm{Alq}_{3}$ layer. The number in inset indicates a layer thickness of TPD and $\mathrm{Alq}_{3}$ in order. Since devices having five different layer thicknesses were made, the devices were named as B1, B2, B3, B4, and B5. Here, a letter " $B$ " designates a bottom-emission device. Figure 1(a) shows a rectifying behavior in all the devices. And as the total thickness of the organic layer increases, the characteristic curves shift to the higher voltage, which means that a turn-on voltage shifts to higher one. Figure 1(b) shows the corresponding luminance-voltage characteristics for those shown in Fig. 1(a). Since the behavior of characteristic curves in Fig. 1(a) is similar to that of Fig. 1(b), we can conclude that the luminance of the device is current driven.

Figure 2(a) and (b) show, respectively, the current efficiency and external quantum efficiency as a function of current density obtained from Fig. 1 for the bottomemission devices. The figure shows that the efficiencies are stable above the current density of $20 \mathrm{~mA} / \mathrm{cm}^{2}$ irrespective of the organic layer thicknesses. As shown in the figure, the device B4, in general, gives a higher current efficiency of about $10 \mathrm{~cd} / \mathrm{A}$ and external quantum efficiency of about $1.2 \%$ than the other ones. Thus, we can say that a proper layer
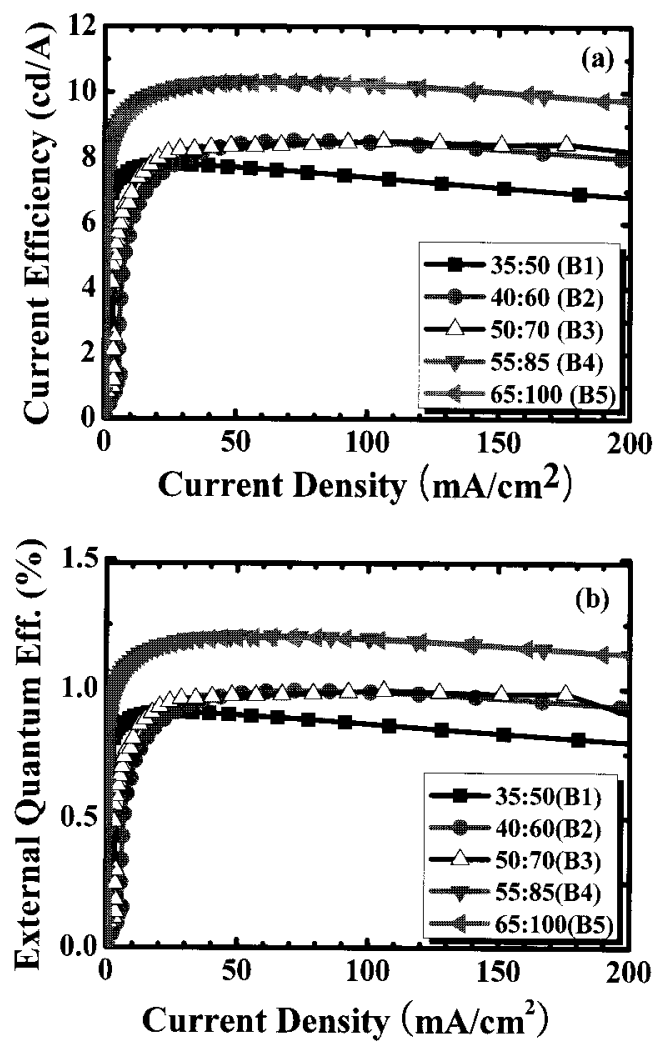

Fig. 2. (a) Current efficiency and (b) external quantum efficiency as a function of current density obtained from Fig. 1 for the bottom-emission devices of ITO/TPD/ $\mathrm{Alq}_{3} / \mathrm{LiF} / \mathrm{Al}$.

thickness of TPD and $\mathrm{Alq}_{3}$ in bottom-emission device is 55 $\mathrm{nm}$ and $85 \mathrm{~nm}$, respectively.

Figure 3(a) and (b) show the view-angle dependent emission spectra as a function of wavelength for the bottom-emission device B4 and top-emission device T4, respectively. Here, a letter " $\mathrm{T}$ " designates a top-emission device. Top-emission devices were made in a structure of glass $/ \mathrm{Al}(100 \mathrm{~nm}) / \mathrm{TPD}(x \mathrm{~nm}) / \mathrm{Alq}_{3} /(y \mathrm{~nm}) / \mathrm{LiF}(0.5 \mathrm{~nm}) / \mathrm{Al}$ $(25 \mathrm{~nm})$ by varying a thickness of TPD and $\mathrm{Alq}_{3}$ layer in a similar way to those of bottom-emission devices. Five devices having different organic-layer thicknesses were made and named as T1, T2, T3, T4, and T5. Here, the organic layer thicknesses for the top-emission devices are the same as those of bottom-emission devices. For example, the device B4 and T4 have the layer thickness of TPD and $\mathrm{Alq}_{3}$ of $55 \mathrm{~nm}$ and $85 \mathrm{~nm}$, respectively. Figure 3(a) shows that for the bottom-emission devices, peak wavelengths of the emission spectra are around $525 \mathrm{~nm}$ irrespective of the view angles. However, Fig. 3(b) shows that there is a blue shift in peak wavelength of the emission spectrum from 560 $\mathrm{nm}$ to $520 \mathrm{~nm}$ as the view angle increases from $0^{\circ}$ to $60^{\circ}$ for the top-emission devices.

Figure 4(a) and (b) show the view-angle dependent peak wavelengths of the emission spectra for the bottom- and top-emission devices, respectively. Figure 4(a) shows that the peak wavelengths for the bottom-emission devices lie near $525 \mathrm{~nm}$, and a full widths at half maxima are about 90 $\mathrm{nm}$ irrespective of the layer thickness of the devices, even though the angle dependent whole behavior of full widths at half maxima is not shown in the figure. Figure $4(\mathrm{~b})$ shows 

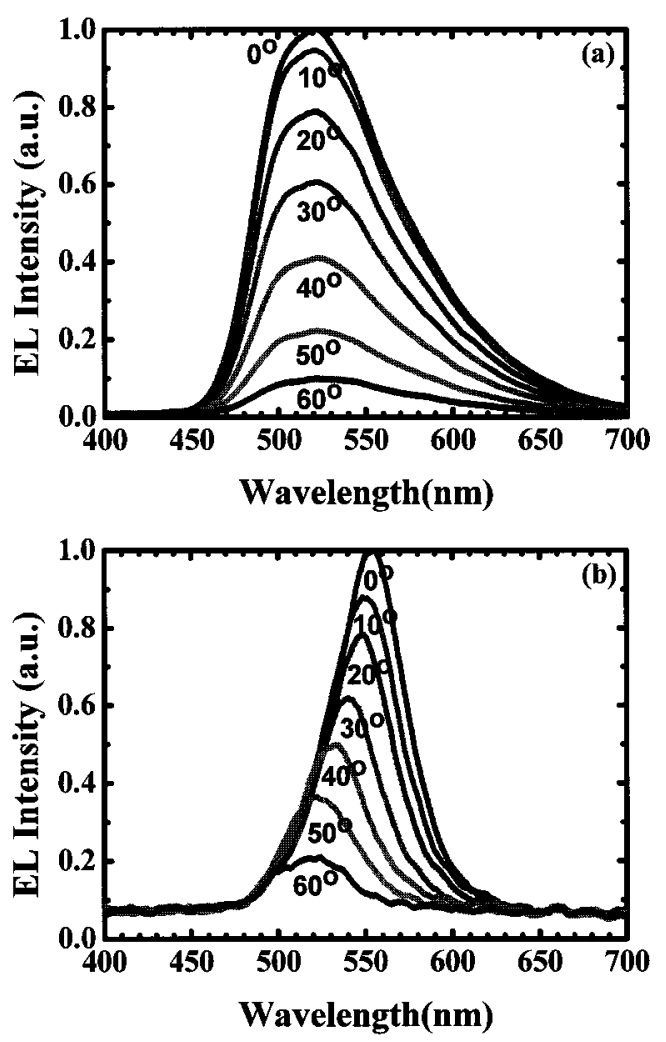

Fig. 3. View-angle dependent emission spectra for (a) the bottomemission device B4 and (b) the top-emission device T4. In both devices, the layer thickness of the TPD and $\mathrm{Alq}_{3}$ is $55 \mathrm{~nm}$ and $85 \mathrm{~nm}$, respectively.

that for the top-emission devices, there is a blue shift in peak wavelength as the view angle increases for the devices T4 and T5 which are thickness than $140 \mathrm{~nm}$. However, there is not much change in peak wavelengths for the devices $\mathrm{T} 1, \mathrm{~T} 2$, and $\mathrm{T} 3$. Thus, it is thought that for the topemission devices thicker than $140 \mathrm{~nm}$ organic layer, a microcavity effect is involved in the emission spectrum. An interpretation of this behavior is still under investigation, and it will be addressed sometime later.

\section{CONCLUSION}

We have studied organic layer-thickness dependent electrical and optical properties for the bottom- and topemission devices. Current density-luminance-voltage characteristics of the bottom-emission devices show that a proper thickness of the TPD and $\mathrm{Alq}_{3}$ layer is $55 \mathrm{~nm}$ and 85 $\mathrm{nm}$, respectively. View-angle dependent emission spectra show that for the bottom-emission device, there is no shift in peak wavelength of the emission spectrum. However, for the top-emission device, there is a blue shift in peak wavelength as the view angle increases when the total layer
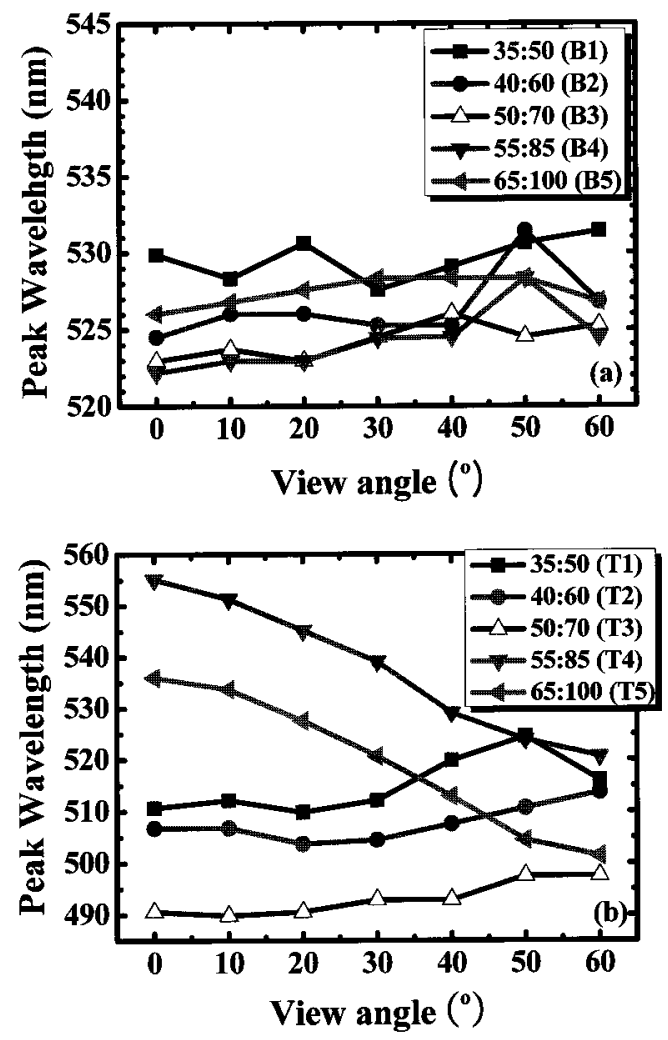

Fig. 4. (a) View-angle dependent peak wavelengths of the emission spectra for several different layer thicknesses of (a) bottom-emission and (b) top-emission devices.

thickness is thicker than $140 \mathrm{~nm}$.

\section{ACKNOWLEDGMENTS}

This work was supported by 2008 Hongik University Research Fund.

\section{REFERENCES}

[1] C. W. Tang and S. A. VanSlkye, Appl. Phys. Lett. 51, 21, 13 (1987).

[2] L. S. Hung, C. W. Tang, and M. G. Mason, Appl. Phys. Lett. 70, 152 (1997).

[3] L. S. Hung, C. W. Tang, M. G. Mason, P Raychaudhuri, and J. Madathil, Appl. Phys. Lett. 78, 544 (2001).

[4] D. G. Lee and J. U. Lee, Trans. EEM 6, 97 (2005).

[5] J. H. Kim, C. H. Suh, M. Y. Kwak, B. O. Kim, and Y. K. Kim, Trans. EEM 6, 221 (2005).

[6] C. H. Cheung, A. B. Djurisic, C. Y. Kwong, H. L. Tam, K. W. Cheah, Z. T. Liu, W. K. Chan, P. C. Chui, J. Chan, and A. D. Rakic, Appl. Phys. Lett. 85, 2944 (2004).

[7] C. J. Lee, Y. I. Park, J. H. Kwon, and J. W. Park, Bull. Kor. Chem. Soc. 26, 1344 (2005).

[8] K. Neyts, Appl. Surf. Sci. 244, 517 (2005). 